\title{
Pembentukan Karakter Peduli Lingkungan melalui Kegiatan Penghijauan pada Siswa MIM Derasan Sempu, Boyolali
}

\author{
Atiqa Sabardila ${ }^{1}$, Anggi Desatria Budiargo ${ }^{2}$, Galih Wiratmoko ${ }^{3}$, Juan Artha Himawan ${ }^{4}$, Aprilia \\ Triutami $^{5}$, Ayu Intansari ${ }^{6}$, Desti Setiyowati ${ }^{7}$, Dizy Hana Tri Cahyani ${ }^{8}$, Ratnawati Handayani ${ }^{9}$, \\ Suistri $^{10}$ \\ ${ }^{1,2,3,4,5,6,7,8,9,10}$ Fakultas Keguruan dan Ilmu Pendidikan, Universitas Muhamamdiyah Surakarta, \\ Indonesia
}

\section{INFORMASI ARTIKEL}

\section{Histori Artikel:}

Submit: 27 April 2020

Revisi: 2 Mei 2020

Diterima: 4 Mei 2020

Publikasi: 6 Mei 2020

Periode Terbit: Desember 2019

\section{Kata Kunci:}

media tanam,

peduli lingkungan,

penghijauan

\section{Correspondent Author:}

Anggi Desatria Budiargo

Fakultas Keguruan dan Ilmu Pendidikan

Universitas Muhammadiyah Surakarta

Indonesia

Email:a320160207@student.ums.ac.id

\begin{abstract}
ABSTRAK
Program penghijauan yang bertujuan untuk meningkatkan kepedulian siswa terhadap lingkungan adalah kegiatan yang dilaksanakan di MIM Derasan Sempu, Kabupaten Boyolali. Ada dua alasan yang mendasari pelaksanaan program ini adalah sebagai berikut: (1) lingkungan sekolah yang gersang, dan (2) kurangnya kesadaran siswa tentang lingkungan sekolah. Hal ini terlihat dari banyaknya siswa yang membuang sampah sembarangan. Artikel ini bertujuan untuk meningkatkan kesadaran siswa terhadap lingkungan melalui program penghijauan dan untuk memperkenalkan jenis media tanam kepada siswa. Dua jenis media tanam digunakan dalam program penghijauan ini, yaitu tanah dan hidrogel. Metode dalam kegiatan ini berupa analisis situasi, identifikasi masalah, menentukan tujuan kerja, rencana pemecahan masalah, pendekatan sosial, pelaksanaan kegiatan, dan evaluasi kegiatan. Hasil kegiatan adalah siswa lebih peka terhadap lingkungan. Hal ini terlihat dari kegiatan mereka melakukan penyiraman tanaman setiap pagi yang dilakukan sesuai dengan jadwal piket. Siswa juga dapat bertanggung jawab untuk memelihara dan merawat tanaman.
\end{abstract}

\section{Pendahuluan}

Sekolah merupakan lingkungan pendidikan yang secara sengaja berjenjang dan berkesinambungan sehingga disebut pendidikan formal. Sekolah adalah suatu tempat atau wahana untuk menyelenggarakan pendidikan yang bertujuan untuk mencapai pendidikan tertentu (Sabdullah, 2010). Sekolah adalah komponen utama seorang anak selain keluarga dan lingkungan sekitar mereka (Mulyana, 2009). Sekolah, selain sebagai tempat untuk mendidik anak dengan pengetahuan, memiliki kewajiban untuk mendidik karakter siswa dan kepedulian siswa pada lingkungan.
Lingkungan sekolah yang memadai, seperti lingkungan yang hijau dan asri, akan menambah suasana belajar yang menyenangkan (Suseno, 2019). Salah satu cara yang dilakukan agar siswa lebih mencintai lingkungan dan meminimalisasi dampak masyarakat terhadap lingkungan yaitu dengan diadakannya pendidikan lingkungan hidup (Mardiana, 2017).

Pengenalan lingkungan sejak dini menjadi solusi utama yang harus dilakukan agar generasi muda memiliki pemahaman tentang lingkungan hidup dengan baik dan benar (Sumarmi, 2008). Pengenalan mengenai lingkungan sejak dini sangatlah berpengaruh terhadap 


\section{doi: 10.23917/bkkndik.v1i2.10763}

anak yang sedang mengalami perkembangan pola pikir (Idrus, et al., 2018).

Demi kelestarian lingkungan manusia mulai menyadari perlunya penghijauan untuk mencegah terjadinya masalah lingkungan di masa depan sehingga dibutuhkan upaya nyata yang harus dilakukan untuk meningkatkan kualitas lingkungan. Salah satunya adalah dengan menumbuhkan sikap peduli lingkungan melalui pendidikan lingkungan kepada anak-anak sejak usia dini (Adriansyah, et al., 2019).

Fenomena tidak peduli lingkungan ditampilkan pada perilaku sehari-hari. Sebagian besar dari peserta didik tidak mampu menghubungkan antara apa yang mereka pelajari dengan bagaimana pengetahuan tersebut digunakan. Seperti peserta didik mengetahui materi pencemaran lingkungan, tetapi mereka masih membuang sampah tidak pada tempatnya, membiarkan lingkungan yang kotor dengan sampah, membiarkan tanaman rusak, dan tidak merawatnya (Sholihah, et al., 2018).

Ditawarkan bahwa pendidikan Lingkungan Hidup mampu memainkan peranannya untuk membentuk manusia yang peduli terhadap lingkungannya sehingga dapat meminimalisasi resiko-resiko kerusakan lingkungan (Simbolon, 2017). Pendidikan lingkungan hidup dapat menghambat adanya polusi dan kegersangan di lingkungan sekitar (Gunawan dan Guslinda, 2019).

Aktivitas manusia tidak mungkin terlepas dari lingkungan karena hakikatnya manusia salah satu komponen yang menempati ruang di lingkungan itu sendiri (Ninsih, et al., 2018). Salah satu cara untuk menumbuhkan rasa peduli terhadap lingkungan dalam diri siswa yaitu dengan cara melakukan penghijauan di sekitar lingkungan sekolah mereka. Penghijauan dalam arti luas adalah segala daya untuk memulihkan, memelihara, dan meningkatkan kondisi lahan agar dapat berproduksi dan berfungsi secara optimal, baik sebagai pengatur tata air atau pelindung lingkungan (Mardiani, 2017). Penghijauan dapat dilakukan apabila ada kemauan dari masing-masing individu. Oleh karena itu, agar lingkungan sekolah menjadi lebih asri dan sehat, guru dan siswa perlu menjaga lingkungan sekitar sekolah. Langkah awal yang dapat dilakukan oleh para guru yaitu menjelaskan kepada para siswa dampak positif dari kegiatan penghijauan.

Menciptakan lingkungan sekolah yang bersih dan sehat dapat diwujudkan asalkan dengan partisipasi seluruh warga sekolah serta dukungan dari pihak internal sekolah. Etika lingkungan hidup yang tercermin pada murid dapat juga berasal dari faktor guru sebagai pendidik dan pengajar (Muslicha, 2015). Kesadaran akan pentingnya pemeliharaan lingkungan seperti penghijauan harus dilakukan sejak dini pada setiap orang.

Di era meningkatnya polusi dan penggunaan berbagai bahan yang dapat merusak alam, kesadaran cinta lingkungan sangat penting ditanamkan sejak dini. Pendidikan Lingkungan Hidup dan kegiatan penghijauan penting diajarkan pada murid SD/MI untuk memperoleh pengetahuan dan kesadaran menjaga lingkungan (Muslicha, 2016). Peduli terhadap lingkungan berarti ikut melestarikan lingkungan hidup dengan sebaik-baiknya, bisa dengan cara memelihara, mengelola, memulihkan, serta menjaga lingkungan hidup (Mardiani, 2017).

Oleh karena itu, kegiatan penghijauan merupakan kegiatan yang tepat untuk diadakan di MIM Derasan, Sempu, Andong, Boyolali dalam rangka meningkatkan kepedulian siswa terhadap lingkungan sekitar. Program ini dilaksanakan karena tim KKN-dik melihat beberapa fenomena yang ditemukan di MIM Derasan, Sempu, Andong, Boyolali, yaitu tidak adanya tanaman di sekitar sekolah dan kondisi halaman sekolah yang gersang serta tidak ada lahan untuk menanam sehingga kegiatan menanam yang dilakukan menggunakan media tanam air dan media tanam tanah dalam pot. Dari hal tersebut diperlukan suatu program kerja yang dapat menarik minat siswa dalam menumbuhkan rasa peduli lingkungan. Salah satunya yaitu melalui program penghijauan yang melibatkan seluruh siswa dan para guru.

\section{Metode Pelaksanaan}

Metode dalam kegiatan ini berupa analisis situasi, identifikasi masalah, menentukan tujuan kerja, rencana pemecahan masalah, pendekatan sosial, pelaksanaan kegiatan, dan evaluasi kegiatan Dalam pelaksanaan kegiatam ada beberapa langkah yang dilakukan untuk pencapaian kegiatan, yakni: (1) penyampaian materi tentang pentingnya peduli terhadap lingkungan dan media tanam, (2) simulasi cara menanam tanaman dan cara menanam dengan mediatanam hidrogel (: hidroponik), (3) anak melakukan praktik per kelompok dengan bimbingan mahasiswa, dan (4) sambil berpraktik, siswa diberi penjelasan tentang lingkungan dan makhluk hidup di sekitar lingkungan. 


\section{Hasil Pelaksanaan dan Pembahasan}

Pelaksanaan program kerja penghijauan dilaksanakan pada minggu ke-2 bulan Februari 2020. Program penghijauan ini dilaksanakan di MIM Derasan Sempu, Andong, Boyolali dengan melibatkan seluruh siswa MIM. Program penghijauan di MIM ini bertujuan untuk membentuk karakter peduli lingkungan pada anak. Program ini tidak hanya mengajarkan siswa untuk mencintai dan menjaga lingkungan, tetapi juga mengajak siswa untuk praktik dan terjun secara langsung sehingga siswa mengetahui bagaimana cara menanam tanaman dengan baik dan merawatnya.

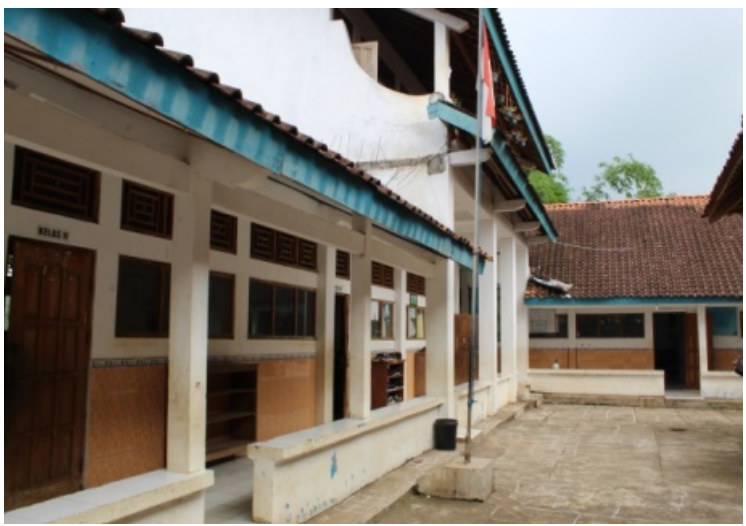

Gambar 1. Keadaan MIM Derasan, Sempu sebelum kegiatan penghijauan

Hasil observasi sebelum diadakan kegiatan penghijauan dapat dilihat pada gambar 1 yang menunjukkan bahwa keadaan sekolah gersang yang ditandai dengan tidak ada tanaman di sekitar lingkungan sekolah. Hal ini juga menunjukkan bahwa masih rendahnya tingkat kepedulian siswa terhadap lingkungan sekitar. Tidak adanya lahan tanah menjadi salah satu penyebab tidak ada tanaman di lingkungan sekolah.

Program penghijauan dimulai dengan penyampaian materi mengenai pentingnya peduli terhadap lingkungan sekitar anak dan penjelasan mengenai media tanam yang akan digunakan untuk praktik dalam kegiatan ini. Setelah menyampaikan materi, mahasiswa memberikan simulasi berupa cara menanam tanaman yang benar dan tepat pada sebuah pot dengan media tanam tanah dan cara menanam tanaman dengan media tanam hidrogel (: hidroponik). Teknik budidaya hidrogel atau hidroponik ini menekankan pemenuhan kebutuhan nutrisi tanaman atau pertanian tanpa tanah (Barat, et al., 2015).

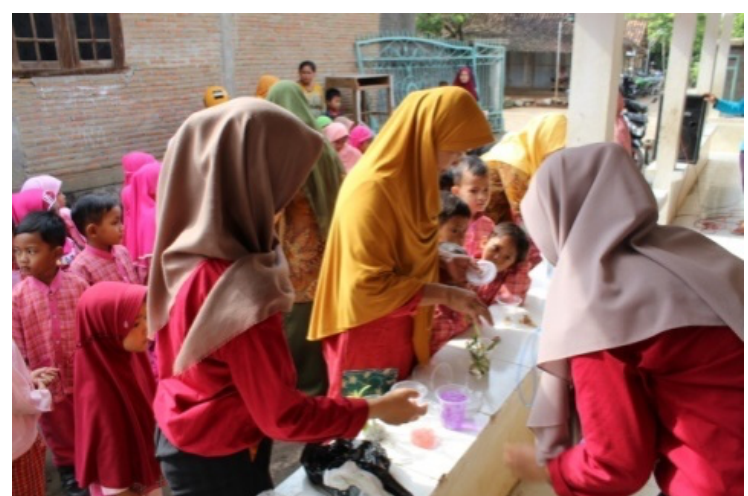

Gambar 2. Simulasi menanam dari mahasiswa KKN

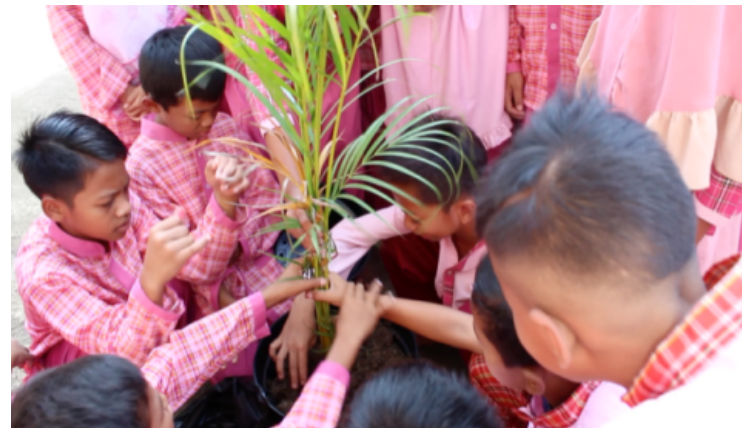

Gambar 3. Antusiasme anak dalam praktik menanam

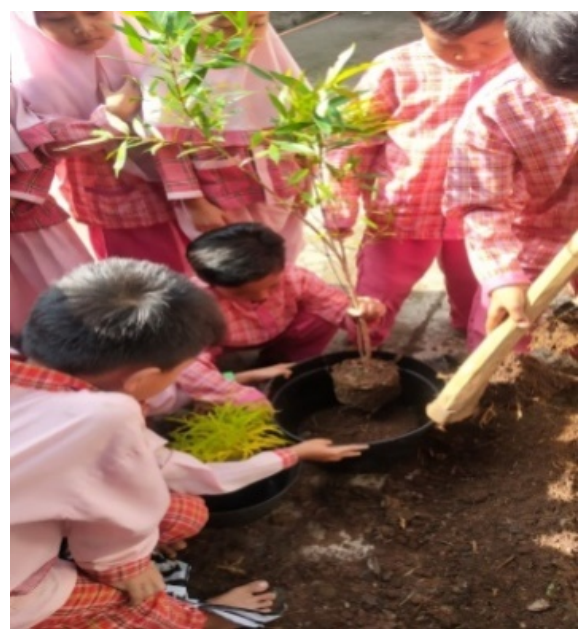

Gambar 4. Anak praktik menanam secara langsung

Setelah diberi penjelasan tentang cara menanam menggunakan dua media tanam, anak melakukan praktik langsung dengan bimbingan mahasiswa KKN. Anak dibagi menjadi beberapa kelompok, yang setiap kelompok terdapat satu mahasiswa yang akan membantu dalam praktik menanam. Antusiasme anak dalam melakukan praktik menanam dari mahasiswa KKN sangat tinggi. Hal ini dapat dilihat dari tanggapnya anak dalam melakukan 


\section{doi: 10.23917/bkkndik.v1i2.10763}

praktik menanam tanaman dengan media tanah dan hidrogel. Melalui kegiatan penghijauan ini siswa secara langsung mengenali jenis tanaman yang mereka tanam. Sambil menanam, mahasiswa KKN juga memberikan penjelasan mengenai lingkungan dan makhluk hidup yang terdapat di sekitar lingkungan.

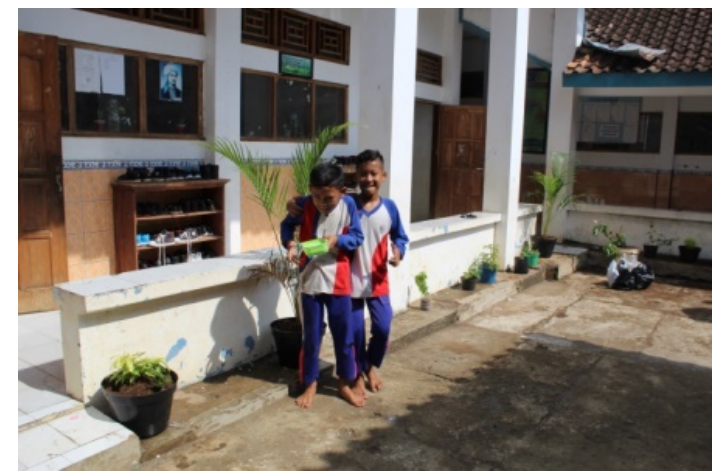

Gambar 5. Anak menata dan menyiram tanaman

A. Tanaman dengan Media Tanam Tanah

Kegiatan penghijauan dilakukan dengan dua media tanam, yaitu media tanam tanah dan media tanam air. Media tanam tanah dilakukan dengan mencampurkan tanah yang ada di pekarangan warga dengan kotoran sapi yang di bawa oleh setiap siswa. Hal ini berguna untuk memberikan pemahaman bahwa kotoran sapi dapat dijadikan pupuk untuk pertumbuhan tanaman.

Tanaman yang ditanam dengan media tanam tanah di antaranya yaitu tanaman pinang hias kuning, lidah buaya, lidah mertua, dan tanaman pucuk merah. Tanaman tersebut cocok ditanam di lingkungan sekolah MIM Derasan karena merupakan tanaman yang tahan panas dan tahan air. Apabila berada di suhu yang tinggi, tanaman tersebut tidak akan mudah layu ataupun mati.

\section{B. Tanaman dengan Media Tanam Hidrogel}

Hidrogel memiliki bentuk bulat dan bertekstur kenyal. Hidrogel tidak larut dalam air, tetapi mampu menyerap air dan akan melepaskan air ketika dibutuhkan oleh tanaman. Tujuan penggunaan media tanam hidrogel ini yaitu mengurangi konsumsi air dan frekuensi penyiraman tanaman.

Kegiatan penghijauan dengan memperkenalkan media tanam hidrogel bertujuan untuk mengedukasi siswa bahwa tanaman tidak hanya dapat ditanam menggunakan tanah, tetapi juga menggunakan hidrogel. Siswa juga menjadi tahu bahwa hidrogel yang dijual di banyak warung ternyata dapat digunakan sebagai media tanam.
Penggunaan hidrogel sebagai media tanam dapat memperindah ruangan karena hidrogel memiliki berbagai warna dari warna ungu, kuning, merah, hingga putih. Siswa menjadi senang melihat tanaman dengan media tanam berwarna warni dan berharap dapat meningkatkan minat belajar siswa. Di samping itu, dengan warna-warni yang dihasilkan lingkungan sekolah dapat menyehatkan mata mereka sehingga dapat lebih tahan untuk aktivitas membaca.

Tanaman yang digunakan untuk media tanam hidrogel berupa bambu hoki. Bambu hoki dimanfaatkan sebagai tanaman hias, baik di dalam rumah maupun di luar rumah. Bambu hoki memiliki kemampuan menyaring udara dan menyerap gas penyebab polusi yang sangat berbahaya bagi kesehatan manusia sehingga bambu hoki tepat digunakan sebagai tanaman hias di dalam kelas.

Melalui kegiatan penghijauan diharapkan anak menjadi lebih peka terhadap lingkungannya dan menjadi lebih peduli terhadap lingkungannya dimulai dari hal-hal yang lebih kecil terlebih dahulu, seperti membersihkan sampah-sampah yang terdapat di sekitar tanaman yang mereka tanam, baik berupa sampah organik maupun sampah anorganik yang selanjutnya sampah tersebut dibuang pada tempatnya.

Tanggung jawab anak dalam merawat tanaman dilihat dari rutinitas anak-anak dalam menyiram tanaman setiap pagi yang dilakukan bergantian sesuai dengan jadwal piket. Untuk tanaman yang berada di pot disiram secukupnya, sedangkan untuk tanaman yang menggunakan media tanam hidrogel setiap hari airnya ditambahkan agar tanaman tidak kekurangan nutrisi. Hal tersebut menunjukkan bahwa melalui kegiatan penghijauan ini secara perlahan dapat menanamkan sikap tanggung jawab terhadap lingkungan sekitar.

Kegiatan penghijauan yang dilakukan di MIM Derasan-Sempu ini dapat meningkatkan kepedulian siswa terhadap lingkungan secara berkelanjutan. Pemanfaatan material ramah lingkungan merupakan tindakan untuk menjaga kelangsungan lingkungan. Hal ini didukung dengan penggunaan barang ramah lingkungan sehingga dapat mendukung kegiatan dalam menjaga kesehatan lingkungan (Ramawangsa, et al., 2020). Penghijauan adalah salah satu kegiatan penting yang harus dilaksanakan secara konseptual untuk melestarikan lingkungan. Penghijauan dalam arti luas adalah segala daya untuk memulihkan, memelihara, dan meningkatkan 
kondisi lahan agar dapat berproduksi dan berfungsi secara optimal.

Peduli terhadap lingkungan berarti ikut melestarikan lingkungan hidup dengan sebaik-baiknya, bisa dengan cara merawat, mengelola, memulihkan serta menjaga lingkungan hidup. Peduli terhadap lingkungan perlu dibentuk sejak usia dini, terutama pada tingkat Sekolah Dasar (SD). Kegiatan penghijauan yang dilakukan di MIM Derasan Sempu dapat meningkatkan sikap peduli lingkungan dalam diri siswa dan rasa tanggung jawab yang besar.

Jika dievaluasi, kegiatan penghijauan atau pelestarian lingkungan ke depan akan semakin semarak manakala kegiatan KKN-Dik menawarkan program kerja yang lebih variatif, seperti membantu menciptakan media edugame tentang cinta lingkungan, membantu menyiapkan bahan ajar bermuatan lingkungan dengan beragam strategi, program green and clean, lomba melukis, membuat seni mural, atau lainnya yang semuanya bermuara pada peningkatan pendidikan karakter tentang cinta lingkungan.

Mengajari anak untuk mencintai lingkungan dapat melalui beragam cara. Satu di antaranya adalah mengajak bermain di luar ruangan. Anak diminta bermain di tanah, lapangan. Anak diminta menyentuh tanah, rumput, bunga, atau tanaman. Hal semacam itu dapat menyadarkan anak bahwa dirinya merupakan salah satu bagian ekosistem yang sekaligus mengembangkan saraf motorik dan sensorik anak. Melibatkan anak dalam menanam pohon di lignkungan sekolah merupakan langkah yang tepat dalam program penghijauan ini.

Ke depan program ini juga amat perlu dikembangkan ke lingkungan rumah siswa. Siswa setiap saat dapat mengurus mereka sehingga tanaman bisa lebih terpelihara. Ini dilakukan untuk mempersiapkan tatakelola lingkungan desa yang tetap asri.

Kegiatan yang tidak kalah penting yang bergayutan dengan cinta lingkungan adalah mahasiswa melakukan pemetaan terhadap kekayaan flora di desa Dearsan-Dempu untuk mengidentifikasi tumbuhan yang paling cocok untuk tumbuh dan berkembang di lokasi itu sehingga penghijauan yang dilakukan sangat relevan. Di samping itu, KKN-Dik dapat berbuat lebih luas lagi dari program ini, yakni dengan meneruskan program pemerintah untuk pelestarian tanaman-tanaman langka. Tanaman-tanaman tersebut dibudayakan di lingkungan sekolah. Jika kegiatan ini sudah lama dirintis oleh beberapa kampus, program itu bisa diturunkan di jenjang sekolah karena tanaman tersebut tersedia di lingkungan mereka. Hal ini penting untuk segera ditindaklanjuti sebelum tanah di pedesaan tergerus oleh perkembangan perumahan desa.

Cinta lingkungan disajikan dalam novel Dari Rahim Ombak yang bercerita tentang perjuangan seorang anak pulau untuk mempertahankan ekosistem lingkungan. Di dalamnya diceritakan para tokoh yang menolak pengeboman dan penghancuran karang sebagai bagian dari ekosistem di laut (Setiawan, et al. , 2017). Dalam menumbuhkan kecintaan terhadap lingkungan mahasiswa dari program apa pun di FKIP dapat menawarkan anak didik tentang hal-hal berikut: pendekatan, strategi, metode, teknik, media, bahan ajar, atau lainnya. Tujuannya adalah menciptakan karakter kuat akan kecintaan mereka terhadap lingkungan.

Pada Pendidikan Anak Usia Dini pun sudah berhasil diterapkan pendekatan saintifik untuk penanaman nilai cinta lingkungan, yakni melalui 5 tahapan, yakni mengamati (menyajikan benda atau objek nyata dari tema yang dibahas untuk diamati anak), menanya (: memberikan kesempatan kepada anak untuk menanyakan hal-hal yang menarik rasa yang menjadi rasa ingin tahu mereka), mengumpulkan informasi mengenai topik yang dibahas tentang beragam sumber, menalar (mendiskusikan untuk membuat simpulan tentang topik yang dibahas dan menggabungkan antara pengetahuan yang telah dimiliki anak dengan pengetahuan yang baru diperoleh), dan mengkomunikasikan (mengkomunikasikan pengetahuan yang diperoleh baik melalui bahasa, cerita, dan , hasil karya (Munawaroh, et al., 2016). Bila demikian, anak usia dini pun sudah dapat menampilkan karya mereka tentang cinta lingkungan melalui beragam media.

Agar tanah pekarangan rumah menjadi lahan produktif, orang tua yang sudah mendapatkan pelatihan tentang pengetahuan, keterampilan, dan mengolah TOGA amat perlu mengawal kegiatan anak mereka. Seperti ibuibu PKK yang dilatih tentang hal itu memberikan hasil yang sangat memuaskan tentang peningkatan pengetahuan, keterampilan, dan mengolah TOGA (Hamidah, et al., 2017).

Cinta lingkungan dapat digarap oleh pakar seni maupun teknologi. Perkembangan mobile learning di Indonesia telah dimanfaatkan untuk menyusun aplikasi Augmented Reality (AR) Edugame Ayo Cintai 


\section{doi: 10.23917/bkkndik.v1i2.10763}

Lingkungan untuk media pembelajaran siswa dengan metode yang dipakai berupa prototyping, bagian dari metode SDLC (System Development Life Cycle). Dalam aplikasi ini terdapat berbagai fitur untuk dimainkan oleh siswa (Purnomo, et al., 2015). Peneliti dan pengajar tari kreatif untuk anak usia dini, Yulianti, menawarkan tari kreatif untuk menanamkan pemahaman cinta lingkungan (Yulianti, 2016).

Guru yang kreatif dapat melihat sampah yang berserakan menjadi objek wisata. Oleh "Wisata Sampah" adalah salah satu kegiatan pada pembelajaran Pendidikan Lingkungan Hidup. Melalui kegiatan ini dapat dimunculkan adalah karakter tanggung jawab, kerja sama dan peduli terhadap lingkungan kehidupan sehari-hari. Ditawarkan suplemen bahan ajar kelas IV dengan mengambil subtema Ayo Cintai Lingkungan (Indrawini, et al., 2017).

Peduli akan lingkungan, khususnya yang bertahun-tahun sudah diterapkan di sekolah pedesaan dan perkotaan. Disadari oleh guru bahwa salah satu karakter yang harus dibentuk sejak dini adalah karakter cinta lingkungan. Pembentukan karakter cinta lingkungan dapat diwujudkan salah satunya melalui Program "green and clean". Program ini bertujuan untuk melatih siswa agar dapat mencintai lingkungannya sejak dini serta dapat memelihara keindahan lingkungan yang dimulai dari lingkungan sekolah. Metode "green and clean" dilakukan melalui Program prapembelajaran di kelas dengan mengajak siswa untuk melakukan Program K3 (: Kebersihan, Keindahan, (dan) Kerapian). Ini berupa program piket bersama di kelas dan lingkungan sekitar sekolah serta belajar merawat tumbuhan yang ada di depan kelas. Metode ini dilakukan agar dapat memperkuat dan meningkatkan kesadaran siswa bahwa lingkungan yang bersih dan indah dapat meningkatkan kenyamanan siswa dalam menjalankan aktivitas di sekolah, khususnya dalam program belajar.

\section{Simpulan}

Berdasarkan kegiatan yang telah dilaksanakan, maka dapat disimpulkan empat hal berikut, Pelaksanaan kegiatan penghijauan dapat menimbulkan rasa peduli terhadap lingkungan dalam diri siswa di MIM DerasaSempu, Andong, Boyolali; Kegiatan penghijauan mendapatkan respon positif dari seluruh warga sekolah, baik dari guru maupun siswa; Siswa mendapat pengetahuan baru mengenai media tanam yang bisa digunakan dalam menanam tanaman; dan Siswa berperan dalam praktik menanam dan menata tanaman di sekitar lingkungan sekolah.

\section{Daftar Pustaka}

Adriansyah, M. A., Sofia, L., \& Rifayanti, R. (2019). "Pengaruh Pelatihan Pendidikan Lingkungan Hidup terhadap Sikap Peduli Anak akan Kelestarian Lingkungan." Psikostudia: Jurnal Psikologi, $\quad$ 5(2), 86-106 https://doi.org/10.30872/psikostudia.v5i2.2281

Agusta, Hida Anel \& Heru Subrata. 2016. "Wisata Sampah" sebagai Strategi Penanaman Karakter Cinta Lingkungan pada Mata Pelajaran Pendidikan Lingkungan Hidup Kelas IV SDN Kresek IV Madiun". Jurnal Pendidikan Guru Sekolah Dasar, 4(2): 131-140. http://mahasiswa.unesa.ac.id

Barat, J., Solikhah, N., Mustaram, A. L., \& Wulanningrum, S. D. (2018). "Area Hijau Edukatif di SD-SMK Perti, Tanjung Gedong, Grogol, Jakarta Barat. Jurnal Bakti Masyarakat Indonesia. $\quad 1(1), \quad 248-255$. https://journal.untar.ac.id

Gunawan, Hadi dan Guslinda. (2019). "Analisis Sikap Peduli Lingkungan Siswa SD Negeri 184 Pekan Baru. Jurnal PGSD, 8 (2): 139-147.

Hamidah, Ririn, Dina Mayan Sari, Dwi Mayasari \& Novendra Halim. (2017). "Penanaman Toga sebagai Wujud Cinta Lingkungan". ABADIMAS ADI BUANA, 01(2): 65-72. DOI: https://doi.org/10.36456/abadimas.vl.i2

Idrus, A., \& Novia, Y. (2018). "Pelaksanaan Nilai Peduli Lingkungan di Sekolah Dasar." Jurnal Gentala Pendidikan Dasar, 3(2), 203-219. https://doi.org/10.22437/gentala.v3i2.6757

Indrawini, Triana, Ach. Aminudin \& Utami Widiarti. (2017). "Pengembangan Bahan Ajar Tematik Subtema Ayo Cintai Lingkungan untuk Siswa Kelas IV SD". Jurnal Pendidikan: Teori, Penelitian, dan Pengembangan, 2(11): 14891497. http://journal.um.ac.id/index.php/jplpp

Mardiana, Dinny. (2017). "Internalisasi Nilai Etika Lingkungan di Sekolah Dasar." Sosio Religi: Jurnal Kajian Pendidikan Umum, 15(1), 1-17. https://ejournal.upi.edu/index.php/SosioReligi/art icle/view/5622

Mardiani, W. (2017). "Pelaksanaan Kegiatan Penghijauan untuk Meningkatkan Kepedulian terhadap Lingkungan di SDN 12 Pekan Baru. Jurnal Ilmu Pendidikan Sosial, Sains, dan Humaniora, 3(2), 269-297. Retrieved from http://ejournal.uin- 
suska.ac.id/index.php/suaraguru/article/view/360 5

Mulyana, R. (2009). "Penanaman Etika Lingkungan melalui Sekolah Perduli dan Berbudaya Lingkungan. Jurnal Tabularasa PPS Unimed, 6(2), 175-180.

Muslicha, A. (2015). "Metode Pengajaran dalam Pendidikan Lingkungan Hidup pada Siswa Sekolah Dasar (Studi pada Sekolah Adiwiyata di DKI Jakarta). Jurnal Pendidikan, 16(2), 110126. https://doi.org/10.33830/jp.v16i2.342.2015

Ninsih, Tri Rosita, dkk. 2018. "Penddikan Karakter Peduli Lingkungan melalui Program "Mahira Bebas Sampah" di SD Alam Mahira Kota Bengkulu." Jurnal PGSD, I(1), 73-82. http://www.jurnal.ut.ac.id/index.php/jp/article/vie w/342

Ramawangsa, P. A., Prihatiningrum, A., \& Mase, L. Z. (2020). "Pemanfaatan Bahan Ramah Lingkungan untuk Desain Penghijauan Vertikal sebagai Upaya Menciptakan Kenyamanan Termal." Journal of character Education Society, 3(1), 145-152.

Setiawan, Arif \& Hidayah Budi Qur'ani. (2017). "Nilai Karakter Cinta Lingkungan Melalui Karakterisasi Tokoh Pada Novel Dari Rahim Ombak Karya Tison Sahabuddin Bungin." KEMBARA: Jurnal Keilmuan Bahasa, Sastra, dan Pengajarannya, http://ejournal.umm.ac.id/index.php/

Sholihah, H., \& Nadzifah, L. (2018). Aplikasi Pendidikan Lingkungan Hidup bagi Anak Tingkat Sekolah Dasar dalam Membentuk Kepedulian Anak terhadap Lingkungan. Islamic
Review: Jurnal Riset dan Kajian Keislaman, 7(2), 174-190.

https://doi.org/10.35878/islamicreview.v7i2.144

Munawaroh, Hidayatul \& Banar Dwi Retyanto. (2016). “Implementasi Pendekatan Saintifik pada Pembelajaran Cinta Lingkungan Pendidikan Anak Usia Dini (Paud) di Kabupaten Wonosobo". Al-Athfal: Jurnal Pendidikan Anak, 2(2): 13- . http://ejournal.uin-suka.ac.id/tarbiyah/alathfal

Purnomo, Bashid Hery \& Endah Sudarmilah. (2015). “ $A R$ Edugame Ayo Cintai Lingkungan sebagai Media Pembelajaran Siswa Sekolah Dasar. Khazanah Informatika: Jurnal Ilmu Komputer dan Informatika, 1(1): 35-39. DOI: 10.23917/khif.vlil.1180.

Simbolon, B. R. (2017). Paket Materi Pembelajaran Inkuiri dalam Pendidikan Lingkungan Hidup untuk Meningkatkan Perilaku Berwawasan Lingkungan Siswa SD di Jakarta. Jurnal Ilmiah Pendidikan Lingkungan dan Pembangunan, $11(2), 1-20$ https://doi.org/10.21009/plpb.112.01

Sumarmi. (2008). "Sekolah Hijau sebagai Alternatif Pendidikan Lingkungan Hidup dengan Menggunakan Pendekatan Kontekstual." Jurnal Ilmu Pendidikan, 15, 19-25. Retrieved from http://journal.um.ac.id/index.php/jip/article/view/ 7/339

Yulianti, Ratna. 2016. "Pembelajaran Tari Kreatif untuk Meningkatkan Pemahaman Cinta Lingkungan pada Anak Usia Dini". Jurnal Pendidikan dan Kajian Seni, .1(1): 131-140. DOI: http://dx.doi.org/10.30870/jpks.v.1il 